\title{
Railway Route Design in Desert Areas
}

\author{
Jabbar-Ali Zakeri ${ }^{1, *}$, Maryam Forghani ${ }^{2}$ \\ ${ }^{1}$ school of railway Engineering, Iran University of science and Technology, Tehran, Narmak, P. O. box 16846 - 13114, Iran \\ ${ }^{2}$ school of railway Engineering, Iran University of science and Technology
}

\begin{abstract}
Developing transportation infrastructures is the main condition for sustainable development of different regions of a country. In Asian, African \& American countries such as Iran, China and Syria, in rail transportation network development, railway, inevitably, cross through desert areas and dry lands. These areas have their own typical problems \& difficulties among which high temperature, dryness, existing of flowing sands, and... can be mentioned. Flowing sand is one of the serious problems of Railways during operation. For this, it is necessary to gain more recognition on flowing sand movement case including identification sand removal basins (zone), wind blowing direction, and its intensity during year, determining sand movement corridors and recognizing sedimentation basins, when designing the route. Experience shows that crossing railway through flowing sand removal basins as well as sedimentation basins, practically, jeopardize train operation and threatening running safety. Using modern methods to confront and/or halter flowing sands while imposing more costs does not provide sufficient reliability. Therefore, at least as a design necessity and obligation, it is proposed that to prohibit construction of railway crossing through sand removal \& sedimentation basins. And railway should merely cross through flowing sands moving corridors the way that flowing sands may be haltered.
\end{abstract}

Keywords sand dune, track route design, sand movement corridors

\section{Introduction}

In addition to the alignment issues such as up and down gradients, curves, stations etc, designing railway tracks in desert region also calls for the study of sand dune. Sand dunes are the major dilemma and impediment to the development of desert region. Revising technical literature shows the fact that; scores of scientists have investigated in to this problem in various ways[2,6]. In the railway field, only topics related to track maintenance in desert region have been conducted and presented[5,7]. In order to conquer such predicament even manufacturers of mechanized maintenance machines have also designed and produced advanced machineries such as SRM500 and Railvac100[8]. But no comprehensive studies, particularly in the field of railway track design with regard to formation of sand dune, removal zone, sediment zone and movement of sand corridors (due to wind intensity and direction). Considering the experience gained in the Iranian railway[10] which has 4.8 per cent of its total network passing through desert areas, this paper shall summaries and present the necessities for study of wind conditions (direction and strength of wind during the years), status of rainfalls, field surveillance intended for investigation of removal zone-sediment zone-corridors of sand movement before the study of the track alignment and then

* Corresponding author:

Zakeri@ iust.ac.ir (Jabbar-Ali Zakeri)

Published online at http://journal.sapub.org/ajee

Copyright (C) 2012 Scientific \& Academic Publishing. All Rights Reserved select the best possible variant amongst the proposed alternatives. For this purpose the author's intention is to illustrates the conditions of Iranian deserts-rain falls in the desert regions and ultimately present the experience of Iranian railway to slender the choice of best alternative for the railway track alignment.

\section{Iranian Desert Condition Appraisal}

Broad pictures of the desert land of the country are categorized as follows;

$\checkmark$ Active sand dune

$\checkmark$ Salty lands

$\checkmark$ Plain regions

$\checkmark$ Mountain foot region

$\checkmark$ Partial rough mountainous heights overlooking the deserts

\subsection{District of Desert-Furbishing in Iran}

On the basis of existing statistics $35.2 \%$ (573884 Sq.Km) of the total $1629807 \mathrm{Sq} . \mathrm{Km}$ of the countries dray land is as result of Hyper Arid climate and 8.5\% (178245 Sq.Km ) of the countries territory is of none arid climate land. As a result, according to the acceptable existing definition, all together more than $44.1 \%$ of the country's area is out of the circle influenced by desert-furbishing. According to the same definition, the three types of climate i.e. Arid, Semi arid and dry sub-humid which encircle 877678 Sq.Km, do not enclose by desert-furbishing. 


\subsection{Contrast between Iran's Desert and that of the Globe}

If the extent of the world's deserts is considered to be equivalent to that of hyper arid land defined by UNEP (1997), i.e. the regions with an annual average of evaporation and perspiration 20 times the typical yearly rain fall, then the area of the globe's real deserts shall be corresponding to $978.1 \mathrm{Mil}$ Hectare or $7.5 \%$ of the earth's dry land. The positions of these deserts are mainly within the ring of 25 to 35 degree north and south of geographical scale, out which the most important of them are identified as; the great African desert, the Arabian desert, Loot desert in Iran, other desert in India (Rajestan region), the south American desert (Peru and Shellie)[6]. The extent of real desert or hyper arid land in Iran according to Khalili's studies (1982) in the country's water master plan is around 57.4 Mil Hectare or 35.5\% (Table 1, 2)[3].

\subsection{Status of Erosion of Earth in the World}

Demolishment of soil and erosion are the consequences of the dessert-furbishing. Table (3) illustrates the status of soil demolishment in various parts of the world.

\subsection{Causes of Desert-Furbishing}

Desert-furbishing occur under various consequences such as human being doing or by nature. Although the cause can not differentiated but in a given region the main reason(s) and its intensity can be determined. According to modern assessment of desert-furbishing the main causes include; the process of erosion by wind and water, undergoing salty, destruction of plants, compaction, formation of hump in the soil, fall in organic materials and gathering of toxic material in soil[6]. One of the most important causes of action related to desert-furbishing in the world is the obliteration of plants which goes as far back as coming to the existence of human being. Traces of salty soil in Mesopotamia, Hwang Ho valley and Nile which is amongst the initial location of Iranian ancient civilization, China[11] and Egypt are the examples of the most ancient soils undergone soil-furbishing due to water wash[4]. Through cutting and destruction of plants, the soil remains without any cover and erodes by water wash and wind. Top layer of the soil turn out to be firm due to drops of rains and trampling of animals and gradually becomes water non-penetrative. Hence owing to intensified rain fall, the volume of water wash shall aggravate the water erosion processes. Also due to plant destruction, there shall be less Biomass and diminishes the organic material in the soil. This reduction shall cause the decline in the stability of the soil and weaken the its structure and the demolishing process starts. Usually well developed soils with a good plant cover in the natural resources of Iran has a strong structure on the top layer, but diminishing the plants weakens the structure of the soils. This process would cause an increase in the virtual density (compaction), reduction in cracks, cut back water and air penetrability and lessens the amount of air and water in soil. This process in turn causes more dryness and reduces the plants cover.

Table 1. Distribution of dry lands in Iran, Asia and the world

\begin{tabular}{|c|c|c|c|c|c|}
\hline District & Hyper arid land & Arid land & Semi arid land & Dry sub-humid land & Total area \\
\hline The world & 987.1 & 1569.2 & 2035.3 & 1294.7 & 6147.3 \\
\hline Asia & 277.3 & 625.7 & 693.4 & 352.7 & 1949.1 \\
\hline Iran & 57.4 & 47.3 & 32.5 & 8.0 & 145.2 \\
\hline
\end{tabular}

Table 2. Percentage distribution of dry lands in Iran, Asia and the world

\begin{tabular}{|c|c|c|c|c|c|}
\hline District & Hyper arid land & Arid land & Semi arid land & Dry sub-humid land & Total area \\
\hline The world & 7.5 & 12.1 & 17.7 & 9.9 & 47.2 \\
\hline Asia & 6.5 & 14.7 & 16.3 & 8.3 & 45.8 \\
\hline Iran & 35.5 & 29.2 & 20.1 & 4.9 & 89.7 \\
\hline
\end{tabular}

Table 3. Continental distribution of various degrees of soil demolishment in the world (Million Hectare)

\begin{tabular}{|c|c|c|c|c|c|}
\hline Degree of Demolishment District & Little & Average & Intensified & Very Intensified & Total \\
\hline Susceptible regions of desert-furbishing in Africa & 118.0 & 127.2 & 70.7 & 3.5 & 319.4 \\
In other regions & 55.7 & 64.6 & 52.8 & 1.7 & 174.8 \\
\hline Susceptible regions of desert-furbishing in Asia & 156.7 & 170.1 & 43.0 & 0.5 & 370.3 \\
In other regions & 137.8 & 174.2 & 64.6 & 0.0 & 376.6 \\
\hline Susceptible regions of desert-furbishing in Australia & 83.6 & 2.4 & 1.1 & 0.4 & 87.5 \\
In other regions & 13.0 & 1.6 & 0.8 & 0.0 & 15.4 \\
\hline Susceptible regions of desert-furbishing in Europe & 13.8 & 80.7 & 1.8 & 3.1 & 99.4 \\
In other regions & 5.5 & 53.7 & 19.5 & 0.0 & 78.7 \\
\hline Susceptible regions of desert-furbishing in N. America & 13.4 & 58.8 & 7.3 & 0.0 & 79.5 \\
In other regions & 5.5 & 53.7 & 19.5 & 0.0 & 78.7 \\
\hline Susceptible regions of desert-furbishing in S. America & 41.8 & 31.1 & 6.2 & 0.0 & 79.1 \\
In other regions & 63.0 & 82.4 & 18.0 & 0.0 & 164.3 \\
\hline Susceptible regions of desert-furbishing in the World & 427.3 & 470.3 & 130.1 & 7.5 & 1035.2 \\
In other regions & 321.7 & 440.3 & 165.5 & 1.7 & 929.2 \\
\hline Total & 749.0 & 910.6 & 295.6 & 9.2 & 1964.4 \\
\hline
\end{tabular}


On the other hand diminishing the organic material and destruction of the structure of the soil due to the rain fall drops consolidates the surface and may cause 30 to 50 percent increase in surface water level. This change of cycle shall cause further dryness in the soil.

Also decline in the organic materials in soil shall cause a reduction in the activity of Micro organism which in turn reduces fertility and less vegetation grow, hence destructing the earth and causing desert-furbishing. Permanent obliteration of the plants, specially trees, bushes, grasses shall cause lack of shade on the surface of the soil, hence increasing the temperature, creating faster evaporation such that the temperature of the soil surface may increase up to 70 degree centigrade in the dry and semi dry lands. Also destruction of plants in the windy regions shall cause wind erosion, faster evaporation, perspiration and hence rapid dryness.

\section{Dunes of Iran}

Wind sand sediments of Quaterner ( $4^{\text {th }}$ era) on the border of deserts, plains and some closed zone inside Iran are mostly of sandy hills. There are some phenomenon, such as leaf sand, blown sand, silk, corrugated hills, sand pyramids, bushy plants and other type of sands, which sometimes wrongly called dune. The major wind-laid sand deposit can be found in the east plain Loot of Iran with more than 15000 Sq.Km and it is called the sea of sand. (Figure 1)

South of Jazmorian, North of Anarak, West of Beshrooeh, East border of the grate desert, North of Kashan, Kerman, Yazd, Gavekhoni marsh, Ardestan and Gonabad are amongst the regions covered by small and big dunes with an area of 129600 Hectare (Khalili, 1992).

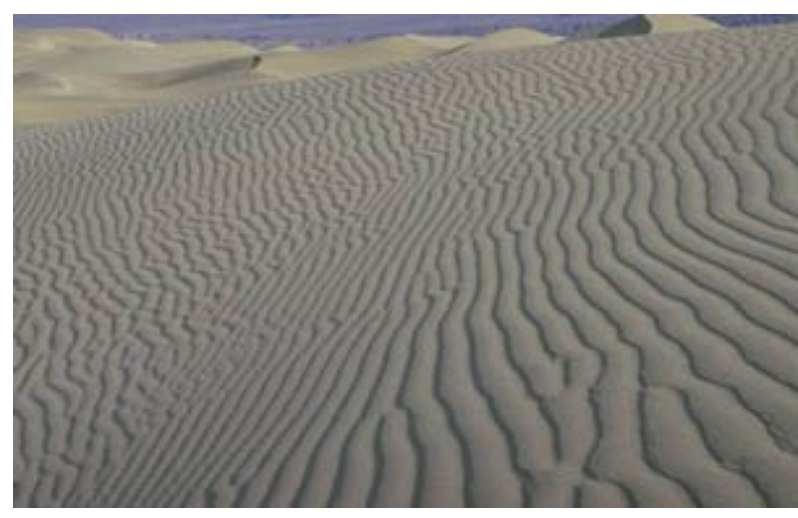

Figure 1. Dunes of Iran

\section{The Manner of Which the Minute Particle of Sands Transfer in the Desert Regions}

\subsection{Movement of Minute Particles in Hovering Form}

This type of movement is especially for Minute particles of sand with an average diameter of less than $0.1 \mathrm{~mm}$. Due to the experiments carried out for grading test, it is anticipated to find this type of particles in Motazar Ghaem station and Tele Hamid.

\subsection{Movement of Minute Particles by Form of Flying}

This type of movement is especially for Minute particles of sand with an average diameter of $0.5 \mathrm{~mm}$.

\subsection{Movement of Minute Particles by Creeping}

This type of movement is especially for Minute particles of sand with an average diameter of more than $0.5 \mathrm{~mm}$.

\subsection{Procedure of Sand Movement}

As every one knows, wind is the main factor of movement of dunes and as it can be seen in Fig1, this process occurs in three steps[1];

1) Taking sand from a region of what is call sand removal basin.

2) The movement is in the direction of wind

3) The settle in a region call sediment basin.

Usually the sediment zone is larger than sand zone. Passing trains through both areas is critical and hazardous. The line is always under thereat of sand filling. Although it is always wise to keep away from constructing railways in such areas, but experience shows that building railway tracks through dune corridors despite of all its problems, is still possible and sand gathering sand on the tracks is much less than when it passes through sand zone or sediment zones.

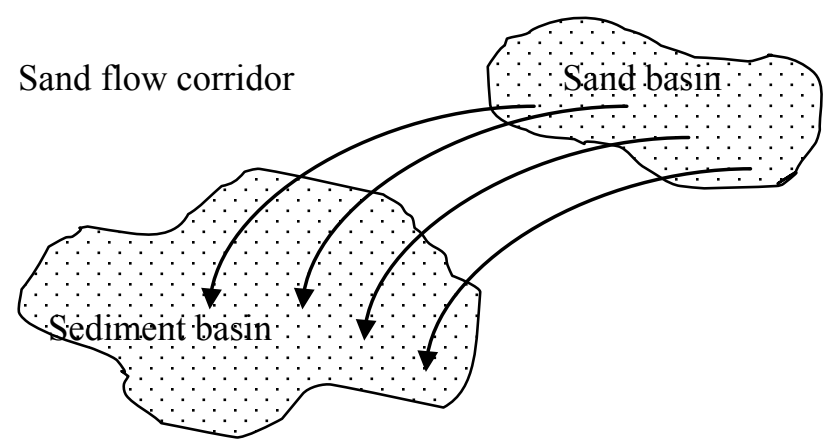

Figure 3. Schematic flow of sand in desert area

\section{Assessment of Climatic Conditions with Respect to the Iranian Railway Lines}

Country's total length of railway line sums up to $9750 \mathrm{Km}$ out of which $416 \mathrm{Km}(4.26 \%)$ passes through deserts (table 4) and wind erosion and movement of sands is the biggest threat for operation of these lines.

Bafgh - Meshed railway line has a main role in national development, attracts transit freight and flourishes the central desert of Iran. This line branches off from Kashmar which is situated on $\mathrm{Km} 853$ of Mashed - Tehran line and after stretching for $440 \mathrm{Km}$ it reaches Tabas and then arrives in Bafgh. Total length of this line including its branch lines is $1000 \mathrm{Km}$ out of which $783 \mathrm{Km}$ is the main line. This line is 
the most vulnerable line with respect to the dune and the operation of trains face major difficulties, especially between Tall-e-Hamid (Km 573+504) and Motazar Ghaem (Km $558+294)$, distance of $15 \mathrm{Km}$. The situation is so hash that trains have to stop several times between the block for the workers to clean the line as track switches can not operate properly. Obviously the trains travel very slowly on this stretch of line. This kind of problems in the region cause accidents and derailment may occur as a result of dunes. Hence in order to prevent such accident, implementation of dune monitoring system seems necessary. Due to drought during this year and recent years, the dune has become worse in central region and desert of Iran, consequently having more negative effect on the railway line, hence; necessitating more attention to the issue of dune and the related troubles it cause with respect to the railway lines in the desert areas.

\section{Wind Condition on the Railway Lines in Desert Area of Iran}

Due to the fact that; wind is the main cause of sand movements, attention to the direction and the velocity of the winds is also of importance. Needs for attention to this issue is especially important when considering various preventive methods such as designing a wall. In this section a summery report of the synoptic stations in sandy region of Iran shall be investigated. The wind status such as number of blows, direction of wind in every month and average velocity of stations situated in Kerman, Tabas, Ahvaz, Bafgh, Naeen, Sarakhs and Shahrood has been looked into and the summary has been illustrated in Table 5 .

Table 4. Sandy areas in Iranian railway Network

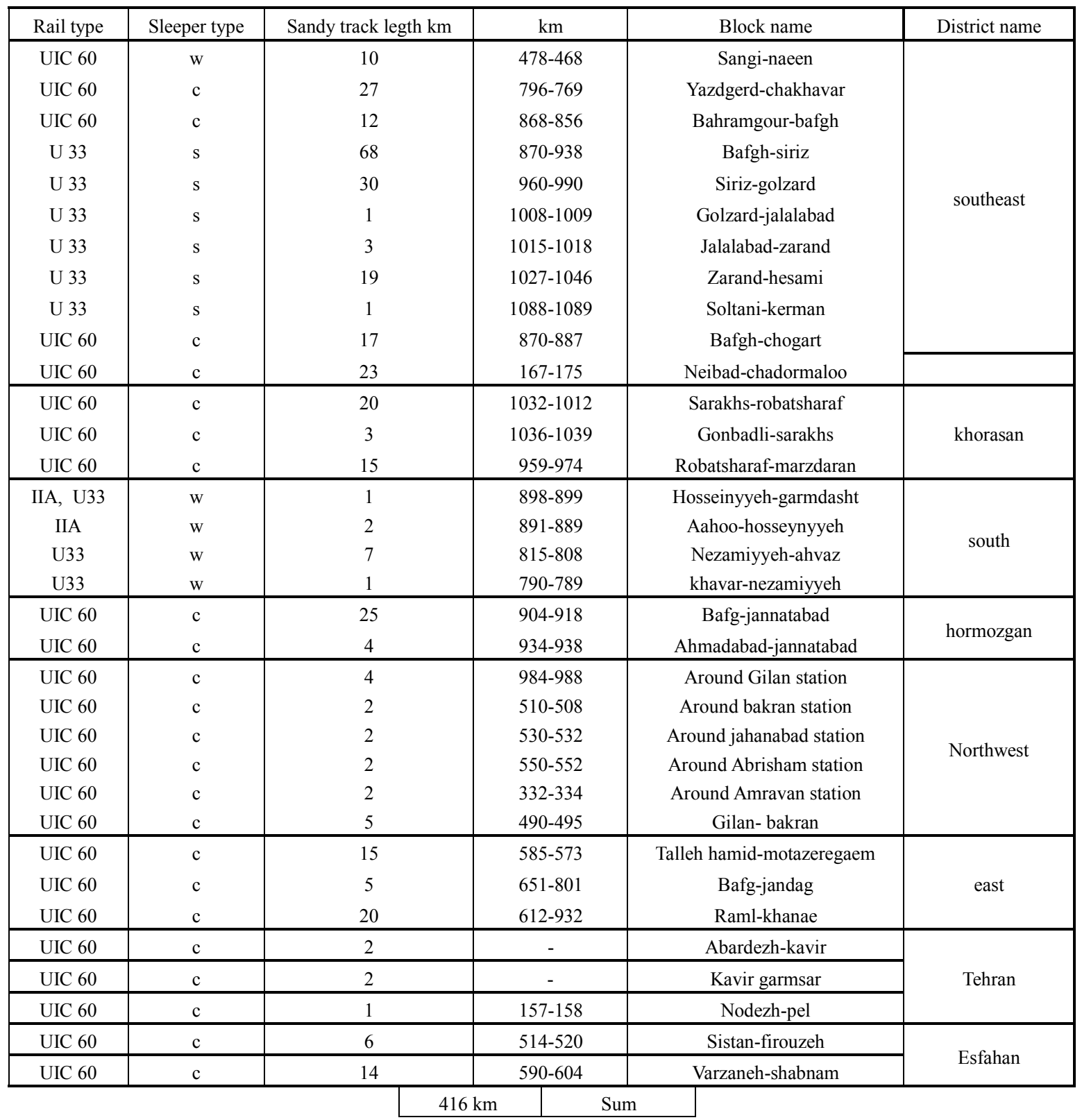


Table 5. Wind and track directions in Iranian deserts areas

\begin{tabular}{|c|c|c|c|c|c|}
\hline Track direction & Wind direction & center & $\mathrm{km}$ & Block name & District name \\
\hline NW-SE & W-NE-E & naeen & $478-468$ & Sangi-naeen & \multirow{11}{*}{ southeast } \\
\hline NW-SE & W-NE-E & naeen & $796-769$ & Yazdgerd-chakhavar & \\
\hline E-W & SE-NW-N & Bafgh & $868-856$ & Bahramgour-bafgh & \\
\hline NW-SE & SE-NW-N & Bafgh & $870-938$ & Bafg-siriz & \\
\hline NW-SE & SE-NW-N & Bafgh & $960-990$ & Siriz-golzard & \\
\hline NW-SE & SE-NW-N & Bafgh & $1008-1009$ & Golzard-jalalabad & \\
\hline E-W & SE-NW-N & Bafgh & $1015-1018$ & Jalalabad-zarand & \\
\hline NW-SE & W-NE-E & kerman & $1027-1046$ & Zarand-hesami & \\
\hline NW-SE & W-NE-E & kerman & $1088-1089$ & Soltani-kerman & \\
\hline NE-SE & SE-NW-N & Bafgh & $870-887$ & Bafg-chogart & \\
\hline E-W & SE-NW-N & Bafgh & $167-175$ & Neibad-chadormaloo & \\
\hline NE-SE & NW-N & Sarakhs & $1032-1012$ & Sarakhs-robatsharaf & \multirow{3}{*}{ khorasan } \\
\hline NE-SE & NW-N & Sarakhs & $1036-1039$ & Gonbadli-sarakhs & \\
\hline E-W & NW-N & Sarakhs & $959-974$ & Robatsharaf-marzdaran & \\
\hline $\mathrm{N}-\mathrm{S}$ & W-NW-SE & Ahvaz & $898-899$ & Hosseinyyeh-garmdasht & \multirow{4}{*}{ south } \\
\hline N-S & W-NW-SE & Ahvaz & $891-889$ & Aahoo-hosseynyyeh & \\
\hline $\mathrm{N}-\mathrm{S}$ & W-NW-SE & Ahvaz & $815-808$ & Nezamiyyeh-ahvaz & \\
\hline $\mathrm{N}-\mathrm{S}$ & W-NW-SE & Ahvaz & $790-789$ & khavar-nezamiyyeh & \\
\hline $\mathrm{N}-\mathrm{S}$ & SE-NW-N & Bafgh & $904-918$ & Bafg-jannatabad & \multirow{2}{*}{ hormozgan } \\
\hline $\mathrm{N}-\mathrm{S}$ & SE-NW-N & Bafgh & 934-938 & Ahmadabad-jannatabad & \\
\hline NE-W & E-NE & Shahroud & $984-988$ & Around Gilan station & \multirow{6}{*}{ Northwest } \\
\hline NE-W & $\mathrm{E}-\mathrm{NE}$ & Shahroud & $510-508$ & Around bakran station & \\
\hline NE-W & E-NE & Shahroud & $530-532$ & Around jahanabad station & \\
\hline NE-W & E-NE & Shahroud & $550-552$ & Around Abrisham station & \\
\hline $\mathrm{N}-\mathrm{S}$ & $\mathrm{E}-\mathrm{NE}$ & Shahroud & $332-334$ & Around Amravan station & \\
\hline NE-W & E-NE & Shahroud & $490-495$ & Gilan- bakran & \\
\hline NE-SW & W-NE-E & Tabas & $585-573$ & Talleh hamid-motazeregaem & \multirow{3}{*}{ east } \\
\hline NE-SW & W-NE-E & Tabas & $651-801$ & Bafg-jandag & \\
\hline NE-SW & W-NE-E & Tabas & $612-932$ & Raml-khanae & \\
\hline
\end{tabular}

\subsection{Number of Blows, Direction and Average Velocity of Various Winds in Sandy Areas of Iran}

Here, winds in various synoptic stations of Ahvaz, Bafgh, Sarakhs, Shahrood, Tabas, Kerman and Naeen has been investigated from the point of view of; average monthly velocity of each directing, i.e. North, North-East, West, South, South-West, West and North-West. The results shown in Table5 are the prevailing average wind velocity. Since in some months of the year, more than four kinds of winds had a maximum values, the prevailing winds are not considered for those months. E.g. In Ahvaz synoptic station, all the winds, except the three types of, South-East, East and North, are all the same and a has a maximum value, prevailing wind is not of such importance. Even though blows and the direction of winds are not preset, but generally speaking one can estimate the annual average and the direction the winds.

Tables of wind conditions and also the status of railway lines have been illustrated below, in order to estimate the situation of lines in the sandy areas.

\section{Iranian Railway Experience in the New Railway Lines}

By looking at the situation of sandy deserts and study of movement of dunes, one can recognize the removal and sediment zones. By keeping away from these zones, although one might lengthen the distance of the route but avoiding the intensity of the vulnerability can be achieved. By a case study on Bam - Zahedan railway line one can see that avoiding the sediment zone, prolonged the route by 20 $\mathrm{Km}$, but has reduced the problems discussed enormously. In the sediment zone nearby this route which has been avoided, an obstacle of $80 \mathrm{~cm}$ in height was erected and the result was $190 \mathrm{~cm}$ of sand gathering in height within only 48 hours, while same obstacle was erected in the worse part of the mentioned railway corridor and the outcome was only $98 \mathrm{~cm}$ of dune. Therefore; firstly one must consider studies particularly in the sandy areas seriously and elaborating a guideline in this file can be of utmost help, secondly always try to avoid the removal and sediment zones. Although there are solutions to control to some extent the problem of dunes but it bears severe cost to the railway[9].

\section{Conclusions}

Primary investigation in to the extent of desert in the world and in Iran shows; $7.5 \%$ dry lands of the world, $6.5 \%$ dry lands of the Asia and $35.5 \%$ dry lands in Iran are of hyper arid lands. Development in these areas is indebted to the development of rail and roads. With regard to the development of railway in these regions, there are no practical criteria to combat the problems and therefore it is necessary to pay attention and elaborate comprehensive research on this issue. Investigation shows, by studding the direction and the intensity of the wind and identifying the removal and sediment zones, one can design an optimize route through dunes 
with minimum dilemma. Previous experience in the Iranian railway shows; one must avoid passing the line through Sediment and removal zones and selecting the route through the corridor of the movement of the sand can be feasible and minimizes predicaments.

\section{ACKNOWLEDGMENTS}

The authors gratefully acknowledge the facilities of the Iran University of Science \& Technology and the sponsorship of the Iranian Railways Company. Thanks due to Eng. Kasaee, head of Rolling Stock Department (Metra consulting company) for their help during the course of this work.

\section{REFERENCES}

[1] Forghani, M, (2007) "Railway track defects in desert area and their solutions", BS.c. Thesis, Iran University of Science \& Technology.

[2] Jabour,A. (1985) "Technical studies the fixation of sand dune in Alkansa-Deirelzor". Syria. Sand transport \& Desertification in arid land World scientific. PP.375-388.

[3] Khalili, A. (1992), "Arid and Hyper Arid", Proceedings of
Iranian Deserts \& Arid.

[4] Le Houero. N. H. (1996).Climate change, Drought and desertification. Journal of Arid Environment, 34:152-176.

[5] Saxsena S. (2004) "A text book of railway engineering", Dhanpat Rai publications.

[6] Stahr, K. and Herrmann, L. (1995) "Origin, deposition and composition of dust and consequences for soil/site properties" in M.V. Oppen, B. Bürkert and B.A. Allison (Eds): The Control of Wind Erosion in Niger: A Case Study.

[7] Zakeri J. A. (2004)'"Track defects in desert area and methods for determining corrective measures" $\mathrm{CD}$ - Proceedings of the $6^{\text {th }}$ International Conference on Railway Engineering, Commonwealth Institute, London.

[8] Zakeri, J. A. (2005), "Special sleeper design for reducing railway track maintenance costs", research Report No. 10341, Iran University of Science \& Technology.

[9] Zakeri J. A. (2012) "Investigation on Railway Track Maintenance in sandy-dry Areas" structure and infrastructure engineering, Volume (8) Issue 2 February, pp. 135-140.

[10] Zakeri J. A. (2007) "Requirements of Railway Route Design in Desert Areas". CD- Proceedings of $8^{\text {th }}$ International conference on Railway Engineering, London.

[11] Zhu Zhenda and Liu Shu. (1988). "Desertification processes and their control in northern China", Chinese Journal of Arid Land Research 1(1), 27-36. 